\title{
The influence of local effects on thermal sensation under non-uniform environmental conditions--gender differences in thermophysiology, thermal comfort and productivity during convective and radiant cooling
}

Citation for published version (APA):

Schellen, L., Loomans, M. G., de Wit, M. H., Olesen, B. W., \& van Marken Lichtenbelt, W. D. (2012). The influence of local effects on thermal sensation under non-uniform environmental conditions--gender differences in thermophysiology, thermal comfort and productivity during convective and radiant cooling. Physiology \& Behavior, 107(2), 252-261. https://doi.org/10.1016/j.physbeh.2012.07.008

Document status and date:

Published: 10/09/2012

DOI:

10.1016/j.physbeh.2012.07.008

Document Version:

Publisher's PDF, also known as Version of record

Document license:

Taverne

Please check the document version of this publication:

- A submitted manuscript is the version of the article upon submission and before peer-review. There can be important differences between the submitted version and the official published version of record. People interested in the research are advised to contact the author for the final version of the publication, or visit the DOI to the publisher's website.

- The final author version and the galley proof are versions of the publication after peer review.

- The final published version features the final layout of the paper including the volume, issue and page numbers.

Link to publication

\footnotetext{
General rights rights.

- You may freely distribute the URL identifying the publication in the public portal. please follow below link for the End User Agreement:

www.umlib.nl/taverne-license

Take down policy

If you believe that this document breaches copyright please contact us at:

repository@maastrichtuniversity.nl

providing details and we will investigate your claim.
}

Copyright and moral rights for the publications made accessible in the public portal are retained by the authors and/or other copyright owners and it is a condition of accessing publications that users recognise and abide by the legal requirements associated with these

- Users may download and print one copy of any publication from the public portal for the purpose of private study or research.

- You may not further distribute the material or use it for any profit-making activity or commercial gain

If the publication is distributed under the terms of Article 25fa of the Dutch Copyright Act, indicated by the "Taverne" license above,

Download date: 26 Apr. 2023 


\title{
The influence of local effects on thermal sensation under non-uniform environmental conditions - Gender differences in thermophysiology, thermal comfort and productivity during convective and radiant cooling
}

\author{
L. Schellen ${ }^{\text {a,* }}$, M.G.L.C. Loomans ${ }^{\text {a }}$, M.H. de Wit ${ }^{\text {a }}$, B.W. Olesen ${ }^{\text {b }}$, W.D. van Marken Lichtenbelt ${ }^{c}$ \\ a Department of the Built Environment, Unit Building Physics and Services, Eindhoven University of Technology, Eindhoven, P.O. Box 513, 5600 MB Eindhoven, The Netherlands

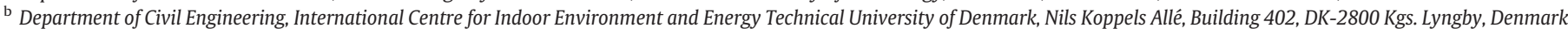

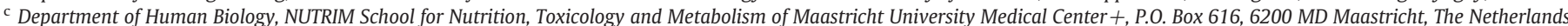

\section{H I G H L I G H T S}

- Application of high temperature cooling systems can result in discomfort.

- Actual thermal sensations differ significantly from predicted thermal sensations.

- Females were more uncomfortable and dissatisfied compared to the male subjects.

- Local effects significantly influence female whole body thermal sensation.

\section{A R T I C L E I N F O}

\section{Article history}

Received 25 April 2012

Received in revised form 13 July 2012

Accepted 20 July 2012

\section{Keywords:}

Non-uniform environmental conditions

Thermal comfort

Physiology

Productivity

Gender differences

Cooling

\begin{abstract}
A B S T R A C T
Applying high temperature cooling concepts, i.e. high temperature cooling $\left(\mathrm{T}_{\text {supply }}\right.$ is $\left.16-20^{\circ} \mathrm{C}\right) \mathrm{HVAC}$ systems, in the built environment allows the reduction in the use of (high quality) energy. However, application of high temperature cooling systems can result in whole body and local discomfort of the occupants. Non-uniform thermal conditions, which may occur due to application of high temperature cooling systems, can be responsible for discomfort. Contradictions in literature exist regarding the validity of the often used predicted mean vote (PMV) index for both genders, and the index is not intended for evaluating the discomfort due to non-uniform environmental conditions. In some cases, however, combinations of local and general discomfort factors, for example draught under warm conditions, may not be uncomfortable.

The objective of this study was to investigate gender differences in thermophysiology, thermal comfort and productivity in response to thermal non-uniform environmental conditions. Twenty healthy subjects (10 males and 10 females, age 20-29 years) were exposed to two different experimental conditions: a convective cooling situation $(C C)$ and a radiant cooling situation $(R C)$. During the experiments physiological responses, thermal comfort and productivity were measured. The results show that under both experimental conditions the actual mean thermal sensation votes significantly differ from the PMV-index; the subjects are feeling colder than predicted. Furthermore, the females are more uncomfortable and dissatisfied compared to the males. For females, the local sensations and skin temperatures of the extremities have a significant influence on whole body thermal sensation and are therefore important to consider under non-uniform environmental conditions.
\end{abstract}

(c) 2012 Elsevier Inc. All rights reserved.

\section{Introduction}

Thermal comfort is an important aspect regarding the satisfaction of occupants with their environment, and therefore regarded as an important building performance indicator. Thermal comfort is a complex phenomenon and it is therefore difficult to satisfy everyone in the same room when no options are allowed to adapt to the conditions. This is due to the large differences between persons, both psychological and

\footnotetext{
* Corresponding author. Tel.: +31 40247 4834; fax: +31 402438595.

E-mail address: l.schellen@tue.nl (L. Schellen).
}

physiological. However, during the design phase of a building it is useful to predict the thermal comfort of the occupants in advance. Fanger [1] studied the thermal conditions necessary to achieve thermal comfort. His studies resulted in the PMV (predicted mean vote) index, expressed as the predicted thermal sensation on the 7-point ASHRAE thermal sensation scale [2], under uniform environmental conditions for a group of persons. This index is based on environmental parameters, activity level (metabolic rate) and clothing insulation, and are included in standards regarding the assessment of thermal comfort [2,3]. These guidelines are widely used by heating and air-conditioning engineers to prescribe and design the thermal environment [4]. Although Brager and de Dear [5] 
and Humphreys and Nicol [6] showed a good agreement between the PMV and actual mean votes in mechanical conditioned buildings, other studies found a discrepancy between the PMV and the actual thermal sensation $[4,7,8]$. These studies argue that differences, among others, are caused by gender and age. According to Fanger [1] females and males have similar preferred thermal neutral temperatures and therefore would prefer the same boundary conditions to achieve thermal comfort. Yet, other results show that the thermoneutral zone of women is shifted upward in comparison to men [9]. Karjalainen [10] concluded from an extensive literature study that in more than half of the studies where females and males have been compared with respect to thermal comfort, females expressed more dissatisfaction than males for the same thermal environments. Furthermore, he found that females are more sensitive to fluctuations around the optimum temperature in comparison to men. Fanger [1] found this as well, but these differences were considered insignificant. However, Karjalainen [10] states, based on literature, that we should no longer neglect the differences in gender while designing indoor environments.

In addition to occupant satisfaction, the energy-use of a building is an important performance indicator as well since one-third of the primary energy in developed countries is used for heating, ventilation and air-conditioning of buildings [11]. The Annex 37 [12] study revealed that an optimal energy use not always results in an increased comfort level. Non-uniform thermal conditions (e.g. vertical temperature differences), which may occur due to application of low energy systems, can be responsible for discomfort [13]. In some cases, combinations of local and general discomfort factors, for example draught under warm conditions, may not be uncomfortable [14]. Under asymmetrical thermal environments higher levels of thermal comfort could furthermore be achieved in comparison to uniform environments $[15,16]$.

It is important to assess thermal comfort adequately in the design phase, to avoid discomfort when the building is erected and in use. In general, the combined effects of convective flows and radiant asymmetries play an important role in the assessment of thermal comfort and are therefore important to study. Yet, the relations between local thermal sensation and comfort, and whole body thermal sensation and comfort, and differences in gender under moderate thermal environments remain unclear. More knowledge on the interaction between the system, indoor climate and human body is indispensable to design optimal systems in the future. Since cooling is becoming increasingly important regarding the conditioning of residential, commercial and public buildings [17], the objective of this research was to study the effects of different cooling principles (convective, in terms of increased air velocity, and radiant, in terms of applying a cold radiant panel) on human local and whole body thermal comfort, physiological responses and productivity. Furthermore, emphasis is on gender differences since several studies have shown that thermal perceptions significantly differ between males and females; which may result in different thermal neutral and comfortable conditions for both genders [4,10,18-21].

\section{Methods}

\subsection{Subjects}

Twenty young adults (20-29 years; $10 \mathrm{M}, 10 \mathrm{~F}$ ) participated in the experiment; their characteristics are presented in Table 1 . All subjects were healthy, normotensive, non-obese, non-smokers and not taking any medication which might alter the cardiovascular or thermoregulatory responses. Eight female subjects were taking oral contraceptives and therefore their hormone level is controlled during the whole menstrual cycle which resulted in an internal body temperature equal to that of females without contraceptives in their luteal phase [22]. Two female subjects who were not taking contraceptives were therefore studied during the luteal phase of their menstrual cycle. Body fat percentage was determined, according to the Siri equation, by means of skinfold
Table 1

Subject characteristics.

\begin{tabular}{lccl}
\hline Subject characteristics & $\mathrm{M}(\mathrm{n}=10)$ & $\mathrm{F}(\mathrm{n}=10)$ & P value \\
\hline Age $($ year $)$ & $24.7 \pm 2.0$ & $24.0 \pm 1.6$ & $\mathrm{~N} . \mathrm{S}$. \\
Height $(\mathrm{cm})$ & $181.8 \pm 8.34$ & $169.6 \pm 8.68^{*}$ & $\mathrm{P}<0.03$ \\
Mass $(\mathrm{kg})$ & $77.3 \pm 8.5$ & $64.7 \pm 9.2^{*}$ & $\mathrm{P}<0.02$ \\
BMI $\left(\mathrm{kg} / \mathrm{m}^{2}\right)$ & $23.5 \pm 3.4$ & $22.5 \pm 2.5$ & N.S. \\
Whole body fat\% (\%) & $16.3 \pm 4.7$ & $18.3 \pm 6.3$ & N.S. \\
\hline
\end{tabular}

Values are presented as mean \pm SD.

$\mathrm{M}$ males, $\mathrm{F}$ females, and BMI body mass index.

* Significant difference between genders $(\mathrm{P}<0.05)$.

thickness [23]. Skin folds were measured at four sites: subscapular, suprailiacal, and at the triceps and biceps [24]. Subjects refrained from alcoholic beverages in the evening and morning prior to the test, but were allowed to eat a small breakfast. During the experiments, the subjects wore standardized clothing, consisting of jogging pants, polo shirt, underpants, socks and low heeled shoes. Clo-values were determined using EN-ISO 9920 [25] and McCullough et al. [26,27]. The total thermal resistance of the clothing ensemble, including desk chair, was calculated to be 0.6 clo. The subjects continuously performed office tasks; their metabolic rate was estimated to be approximately 1.2 met [3].

The volunteers were given detailed information regarding the purpose and the methods used in the study, before written consent was obtained. However, they were not informed on the actual conditions they were exposed to.

\subsection{Experimental conditions}

Two different cooling cases were studied; cooling through convection $(C C)$ and cooling through radiation $(R C)$. Convective cooling occurred through an increased air velocity, where the supply temperature equaled the room temperature. Radiant cooling occurred through applying a cold radiant panel (ceiling). Both cases were designed to achieve a predicted neutral thermal sensation $(\mathrm{PMV} \approx 0)$.

\subsubsection{CC-cooling through convection}

Olesen [14] has shown that an increased air velocity (draught under warm conditions) is not necessarily uncomfortable and can provide a comfortable cooling situation. Furthermore, if air-conditioning is not necessary within certain temperature limits, allowing an increased air-velocity around the occupant for cooling purposes could reduce the energy-use. The exposure conditions for the $C C$ situation are given in Table 2, separated for male and female subjects. The measured air velocities during the measurements with females were higher because of practical limitations regarding the adjustment of the surface area. Males also joined in another experiment. Therefore the switching of the inlet surface area differed between males and females.

\subsection{2. $R C$-cooling through radiation by the ceiling}

Radiant ceiling panels are considered as an interesting alternative to active convective cooling (supplying cold air) to improve thermal

Table 2

Case summary, case $C C$.

\begin{tabular}{lcc}
\hline Variable & $\mathrm{M}(\mathrm{n}=10)$ & $\mathrm{F}(\mathrm{n}=10)$ \\
\hline Operative temperature $\left[{ }^{\circ} \mathrm{C}\right]$ & $25.2 \pm 0.2$ & $25.3 \pm 0.2$ \\
Air temperature $\left[{ }^{\circ} \mathrm{C}\right]$ & $25.5 \pm 0.2$ & $25.5 \pm 0.3$ \\
Relative humidity $[\%]$ & $34 \pm 1.1$ & $32 \pm 0.9$ \\
Air velocity $[\mathrm{m} / \mathrm{s}]$ & $0.23 \pm 0.03$ & $0.32 \pm 0.02$ \\
Wall temperature $\left[{ }^{\circ} \mathrm{C}\right]$ & $25.0 \pm 0.1$ & $25.1 \pm 0.3$ \\
Floor temperature $\left[{ }^{\circ} \mathrm{C}\right]$ & $24.9 \pm 0.1$ & $25.2 \pm 0.1$ \\
Ceiling temperature $\left[{ }^{\circ} \mathrm{C}\right]$ & $25.0 \pm 0.1$ & $25.1 \pm 0.4$ \\
Mean radiant temperature $\left[{ }^{\circ} \mathrm{C}\right]$ & $25.0 \pm 0.1$ & $25.1 \pm 0.2$ \\
PMV [-] & $0.3 \pm 0.05$ & $0.1 \pm 0.07$ \\
\hline
\end{tabular}

Values are presented as mean \pm SD. 
Table 3

Case summary, case $R C$.

\begin{tabular}{lll}
\hline Variable & $\mathrm{M}(\mathrm{n}=10)$ & $\mathrm{F}(\mathrm{n}=10)$ \\
\hline Operative temperature $\left[{ }^{\circ} \mathrm{C}\right]$ & $24.4 \pm 0.1$ & $24.3 \pm 0.1$ \\
Air temperature $\left[{ }^{\circ} \mathrm{C}\right]$ & $24.2 \pm 0.1$ & $24.1 \pm 0.1$ \\
Air velocity $[\mathrm{m} / \mathrm{s}]$ & $0.14 \pm 0.01$ & $0.13 \pm 0.00$ \\
Relative humidity $[\%]$ & $33 \pm 1.0$ & $33 \pm 0.1$ \\
Wall temperature $\left[{ }^{\circ} \mathrm{C}\right]$ & $23.6 \pm 0.0$ & $23.2 \pm 0.1$ \\
Floor temperature $\left[{ }^{\circ} \mathrm{C}\right]$ & $28.9 \pm 0.1$ & $28.9 \pm 0.0$ \\
Ceiling temperature $\left[{ }^{\circ} \mathrm{C}\right]$ & $18.0 \pm 0.2$ & $17.9 \pm 0.1$ \\
Mean radiant temperature $\left[{ }^{\circ} \mathrm{C}\right]$ & $24.7 \pm 0.0$ & $24.5 \pm 0.1$ \\
$\Delta$ Plane radiant temperature $($ floor-ceiling $)\left[{ }^{\circ} \mathrm{C}\right]$ & $8.1 \pm 0.2$ & $8.3 \pm 0.1$ \\
$\Delta$ Air temperature left $(1.1 \mathrm{~m}-0.1 \mathrm{~m})\left[{ }^{\circ} \mathrm{C}\right]$ & $0.6 \pm 0.0$ & $0.7 \pm 0.0$ \\
$\Delta$ Air temperature right $(1.1 \mathrm{~m}-0.1 \mathrm{~m})\left[{ }^{\circ} \mathrm{C}\right]$ & $0.4 \pm 0.0$ & $1.0 \pm 0.0$ \\
PMV $[-]$ & $0.1 \pm 0.02$ & $0.0 \pm 0.00$ \\
PD vertical air temperature difference $[\%]$ & Left: & Left: \\
& $0.1 \pm 0.0$ & $0.1 \pm 0.0$ \\
& Right: & Right: \\
PD cool ceiling $[\%]$ & $0.2 \pm 0.0$ & $0.2 \pm 0.0$ \\
\hline
\end{tabular}

Values are presented as mean $\pm \mathrm{SD}$.

comfort and to reduce the energy consumption in buildings [28,29]. Furthermore, they can be used during winter for heating. These panels impose a non-uniform thermal environment, introduce temperature asymmetries and can cause vertical temperature gradients $[12,29]$. The exposure conditions for the $R C$ condition are given in Table 3. The setup conditions for the $R C$ case were designed to achieve a PMV-index of 0 . As supply air temperature conditions where controlled at the corresponding operative temperature, the floor temperature was raised to compensate for the cooling provided by the ceiling. The resulting vertical temperature gradient and radiant asymmetry can cause a percentage of dissatisfied (PD) due to local discomfort according to EN-ISO 7730 [3]. As it can be derived from results shown in Table 3, the vertical air temperature difference and radiant asymmetry (cold ceiling) where within the $\mathrm{PD}<10 \%$ range.

During both cases fresh air, conditioned by an air-handling unit (Verhulst Klimaattechniek BV, Drunen, The Netherlands) at a constant temperature of $24.5{ }^{\circ} \mathrm{C}$ and $30 \% \mathrm{RH}$, was supplied through mixing ventilation. The case differences between genders are considered small.

\subsection{Protocol}

Subjects visited the climate chamber (Fig. 1) during winter (December 2010-March 2011, average outside temperature ranged from -1.4 to $\left.6.7^{\circ} \mathrm{C}[30]\right)$. The test room is situated at the laboratory of the unit Building Physics and Services of the department of the Built Environment at the Eindhoven University of Technology. The dimensions of the room are similar to a standard office room: $3.6 \times 5.4 \times 2.7 \mathrm{~m}^{3}(\mathrm{~W} \times \mathrm{L} \times \mathrm{H})$.

For this study, the subjects visited the climate chamber for $4 \mathrm{~h}$ during the morning or afternoon. The male subjects, furthermore, visited the climate chamber two times more for another related experiment. The order of all cases was randomized. After written consent was obtained, the subjects swallowed a temperature telemetric pill and changed clothes. Next, the subjects performed a light exercise of 5 min to obtain skin vasodilatation in order to ensure that all subjects entered the climate room in an equal thermal state. Vasodilatation was assessed by the skin temperature difference between forearm and top of the forefinger [31,32]. Furthermore, the subject characteristics (height, weight, and fat percentage) were determined and the skin temperature sensors were attached.

After entering the climate room, the experiment started with an acclimatization period (30 min). During this period they received an instruction regarding the use of the questionnaires. After completion of the first case a new acclimatization period of $30 \mathrm{~min}$ followed (as preparation for the second case). During this period the subjects had the opportunity to visit the rest room. A detailed time line is given in Fig. 2.

\subsection{Measurements}

\subsubsection{Physical and physiological measurements}

Skin temperature was measured at $1 \mathrm{~min}$ intervals by wireless iButtons (Thermochron iButton, DS1291H, Maxim, CA, Sunnyvale, USA,
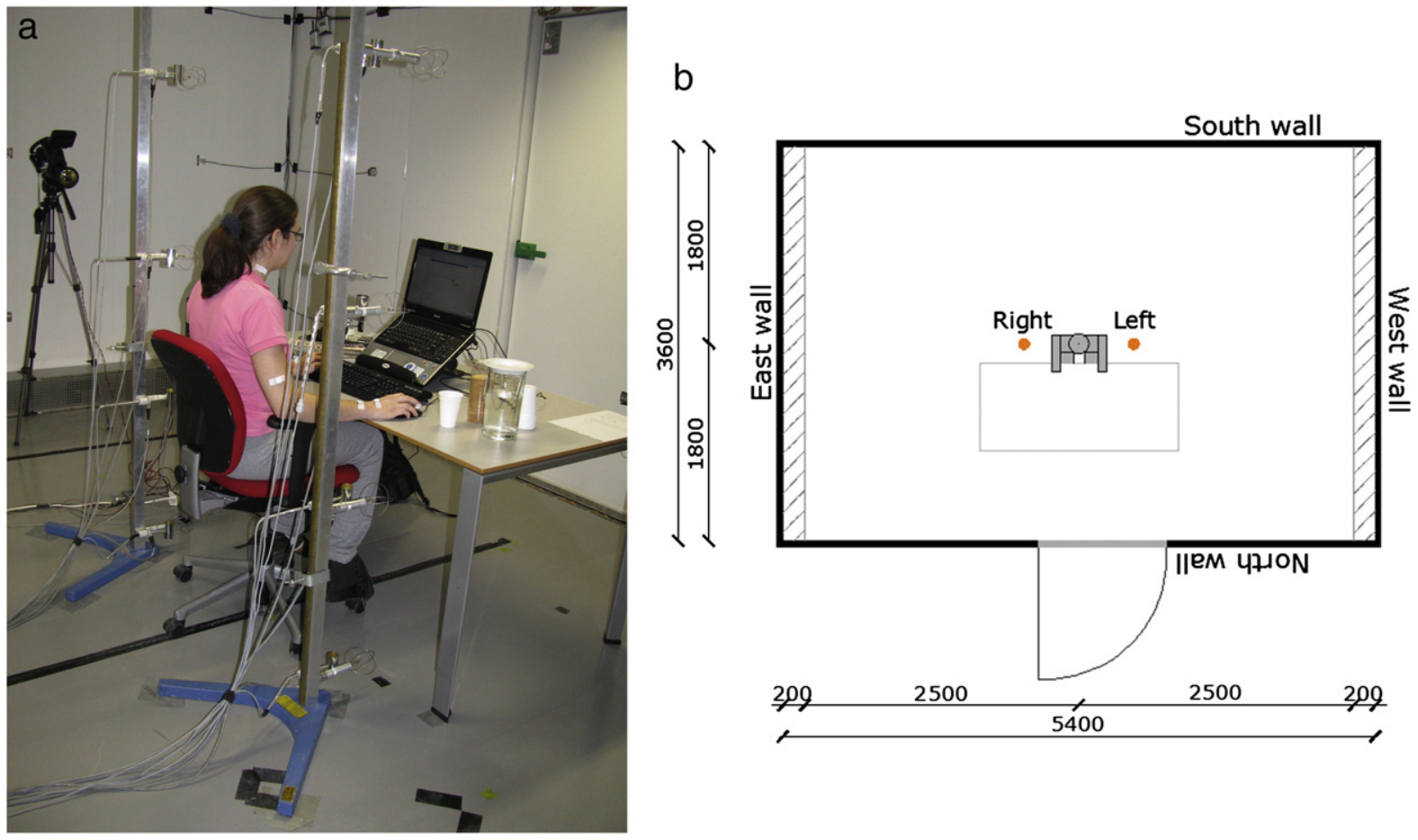

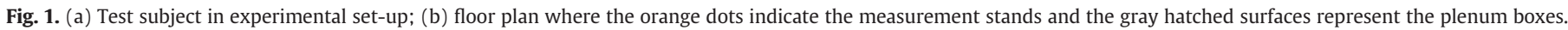




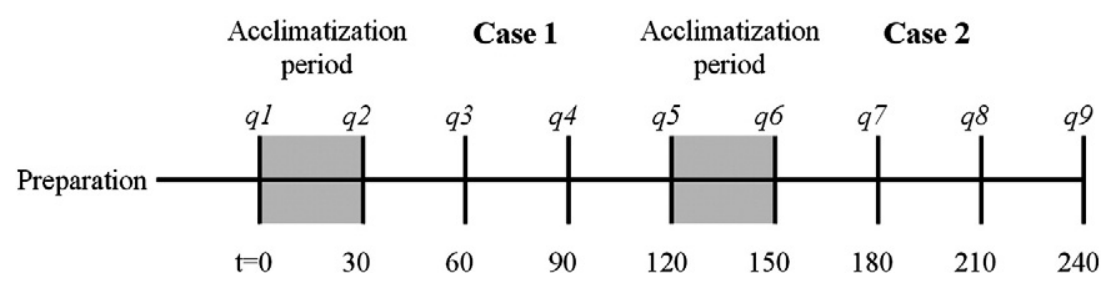

Fig. 2. Time line of measurement protocol; $q$ is representing the questionnaire moments.

accuracy $\pm 0.1^{\circ} \mathrm{C}$ ) at 24 locations to assess possible differences between the left and right sides of the human body [33]. iButtons were attached with semi-permeable adhesive tape (Fixomull; BSN medical gmbh, Hamburg, Germany). Mean skin temperature was calculated according to the 14-point weighing as proposed by EN-ISO 9886 [34] (Points 1-14, Fig. 3a). Distal skin temperature was calculated as average of instep, ankle, finger tip, hand, and forehead skin temperatures. To avoid a disproportional distribution, forehead and instep temperatures had a weighing factor of 2 . Proximal skin temperature was calculated as an average of the scapula, paravertebral, upper chest, and abdomen skin temperatures. Core temperature was determined by measuring the intestinal temperature at a $1 \mathrm{~min}$ interval through an ingestible telemetry pill (CorTemp, Ingestible Core Body Temperature Sensor, HT150002, HQ Inc., Palmetto, FL, USA, accuracy $\pm 0.1{ }^{\circ} \mathrm{C}$ ).

Air temperature (NTC Thermistor, type SC95, accuracy $\pm 0.1{ }^{\circ} \mathrm{C}$ ), relative humidity (RH) (Humidity Sensors, Honeywell HIH-4000 series), air velocity (hot sphere anemometer, Dantec, estimated accuracy 15\% [35],) surface temperature (NTC Thermistor, U-type EU-UU-10-PTFE, accuracy $\pm 0.1{ }^{\circ} \mathrm{C}$ ) carbon dioxide (Carbon Dioxide Transmitter, Vaisala 0-2000 ppm), and illuminance (Lux meter, Hager model E2) were measured according to EN-ISO 7726 [36]. Air temperature, RH, and air velocity were measured on two comfort stands at 0.1, 0.6, 1.1 and $1.7 \mathrm{~m}$ height. These comfort stands were placed on the left and right sides of the subject, at a distance of $0.2 \mathrm{~m}$. The average surface temperature at each surface was derived from nine measurement points on each surface (at a grid of $3 \times 3$ ). The mean radiant temperature was determined according to the surface temperatures and view factors related to the position of the subject. a

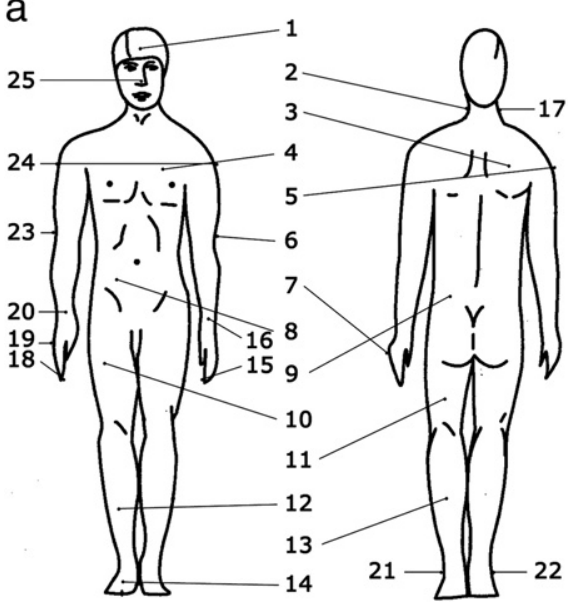

b

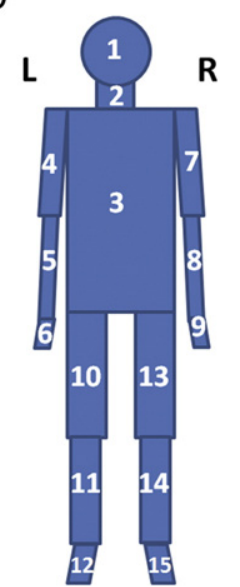

Fig. 3. (a) Measurement sites' skin temperature; (b) schematic representation of body parts to assess local thermal sensation and comfort.

\subsubsection{Questionnaires}

Every $30 \mathrm{~min}$, starting at $\mathrm{t}=0 \mathrm{~min}$, the test subjects filled in a questionnaire. Thermal sensation votes, both global and local for each body part (Fig. 3b), were asked on a continuous 7-point ASHRAE thermal sensation interval scale, where each point on the line could be marked (Fig. 4) [2]. Global and local thermal comfort were asked on a ISOdefined 4-point thermal comfort scale [37]. Visual analogue scales (VAS) were used to assess adverse perceptions and the perceived indoor environment [38]. A question to assess perceived stress was included as well.

Productivity was assessed using the Remote Performance Measurement (RPM) method [39]. Within this method, the productivity was estimated by two simulated office tasks: text typing and addition. The questionnaires and simulated office tasks were presented in Dutch to the subjects through an Internet browser.

\subsubsection{Data analysis}

For the statistical analyses, physical and physiological responses of the whole measurement period, except the acclimatization period, were used (i.e. Case 1: $t=30$ to $t=120$ and Case 2: $t=150$ to $t=240$; Fig. 2). The subjective responses were analyzed from four questionnaires of each case (i.e. Case 1: q2-q5 and Case 2: q6-q9; Fig. 2). The differences in physical and physiological measurements were tested using ANOVA. Differences in subjective responses between the two experimental cases were studied using the non-parametric Wilcoxon signedrank test. Spearman-rho tests were used to study the correlations between local skin temperatures (averaged over $10 \mathrm{~min} ; 5 \mathrm{~min}$ prior to the questionnaire and 5 min during the subjects filled in the questionnaire), local thermal sensations, and whole-body thermal sensation. Significant effects are reported for $\mathrm{P}<0.05$. The commercially available software package PASW Statistics 18.0 (SPSS Inc., Chicago, USA) was used to analyze the data.

\section{Results}

\subsection{Physiological measurements}

Mean, distal and proximal skin temperatures of the females were significantly lower $(\mathrm{P}<0.001)$ than that of males in both cases (CC and RC; Table 4 and Fig. 5). Besides, mean core temperature of the females was significantly higher in comparison to that of the males in both cases (Table 4). Mean, distal and proximal skin temperatures of the males were significantly lower during $R C$ in comparison to $C C$. Mean and distal skin temperatures of the females were significantly higher during $R C$ in comparison to $C C$. Furthermore, female core temperature was significantly lower during $R C$ in comparison to $C C$. The physiological responses of the males are constant during both cases (Fig. 5). During CC case (Fig. 5a) the mean, distal and proximal skin temperatures for females show a drop after $\mathrm{t}=80$ while no

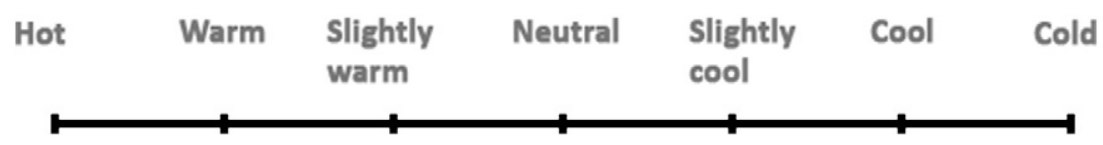

Fig. 4. Continuous 7-point ASHRAE thermal sensation interval scale [2]. 
Table 4

Mean, distal and proximal skin temperatures of males and females during both experimental conditions.

\begin{tabular}{|c|c|c|c|c|}
\hline \multirow[b]{2}{*}{ Variable } & \multicolumn{2}{|l|}{ Case CC } & \multicolumn{2}{|l|}{ Case $R C$} \\
\hline & $M(n=10)$ & $F(n=10)$ & $M(n=10)$ & $F(n=10)$ \\
\hline $\begin{array}{l}\text { Mean skin } \\
\text { temperature }\left[{ }^{\circ} \mathrm{C}\right]\end{array}$ & $33.1 \pm 0.07$ & $32.2 \pm 0.44^{*}$ & $32.8 \pm 0.05^{\wedge}$ & $32.5 \pm 0.09^{*}$ \\
\hline Core temperature $\left[{ }^{\circ} \mathrm{C}\right]$ & $37.0 \pm 0.05$ & $37.5 \pm 0.04^{*}$ & $37.0 \pm 0.04^{\wedge}$ & $37.4 \pm 0.04^{*}, \wedge$ \\
\hline $\begin{array}{l}\text { Distal skin } \\
\text { temperature }\left[{ }^{\circ} \mathrm{C}\right]\end{array}$ & $32.0 \pm 0.17$ & $29.5 \pm 0.28^{*}$ & $31.3 \pm 0.26^{\wedge}$ & $30.2 \pm 0.56^{*}$ \\
\hline $\begin{array}{l}\text { Proximal skin } \\
\text { temperature }\left[{ }^{\circ} \mathrm{C}\right]\end{array}$ & $34.1 \pm 0.12$ & $33.2 \pm 0.50^{*}$ & $33.7 \pm 0.13^{\wedge}$ & $32.3 \pm 0.08^{*}$ \\
\hline
\end{tabular}

Values are presented as mean $\pm \mathrm{SD}$.

* $\mathrm{P}<0.001$ versus males.

$\mathrm{P}<0.001$ versus $C C$ case.

increase in core temperature could be observed. During $R C$ case (Fig. 5b) the distal skin temperature of the females decreased during the experiment, which is caused by a decrease in skin temperature of the hands (increase in vasoconstriction, Fig. 6). The extent of vasomotion, the difference (gradient) between fingertip and forearm temperatures, during both cases for males and females is represented in Fig. 6. Positive values indicate vasoconstriction (forearm temperature is higher than finger tip temperature), while negative values indicate vasodilatation.

The fingertip-underarm gradient for the females reflects continuously vasoconstriction during both cases at both left and right sides of the body. Furthermore, the right side of the body is significantly more vasoconstricted in comparison to the left side. For the males this effect was only observed during the $R C$ case, the fingertip-underarm gradient at the right side was significantly higher in comparison to the left side (mean $1.2 \pm 0.58{ }^{\circ} \mathrm{C}$ vs $-0.4 \pm 0.58$ respectively). The distribution of mean local skin temperatures during both cases, separately for males and females, is represented in Fig. 7. The majority of the local skin temperatures of the females are significantly lower during both cases in comparison to the local skin temperatures of the males $(\mathrm{P}<0.01)$. The skin temperatures of arms and hands show the largest differences between males and females.
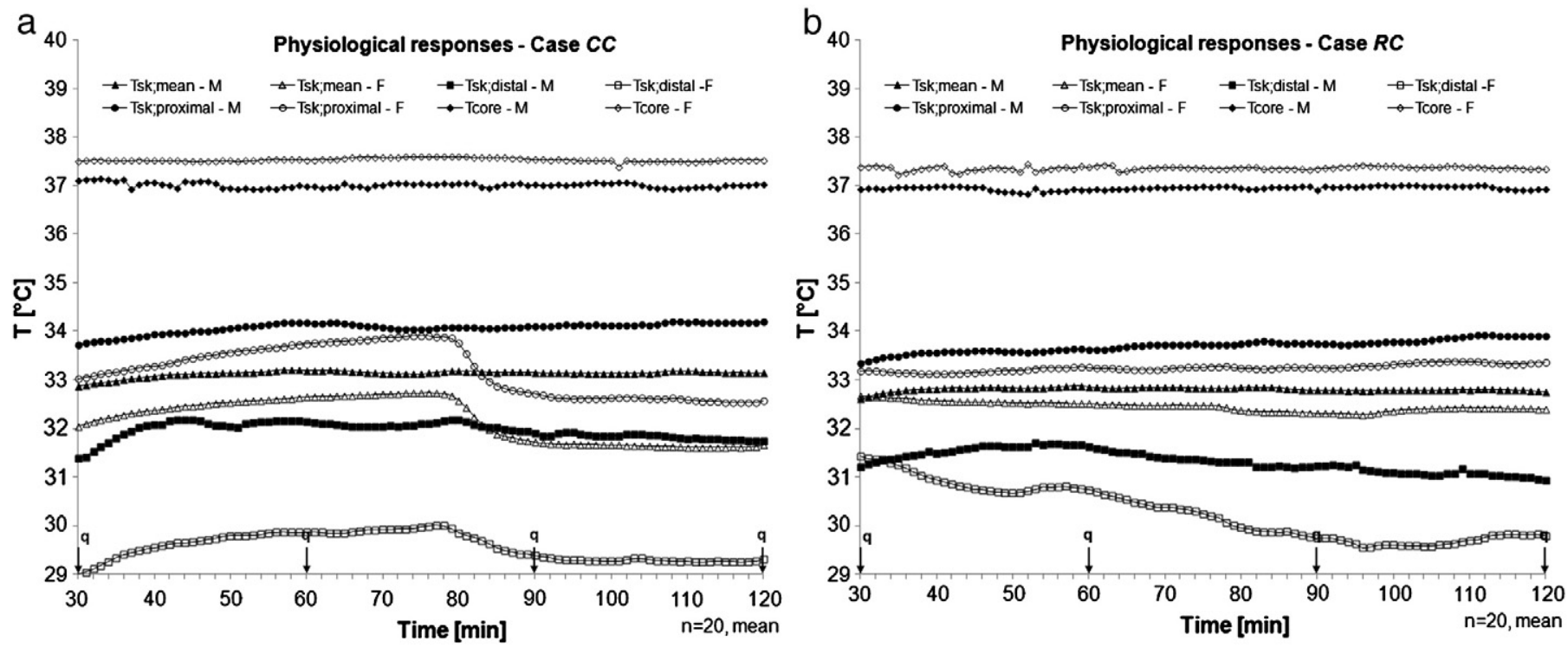

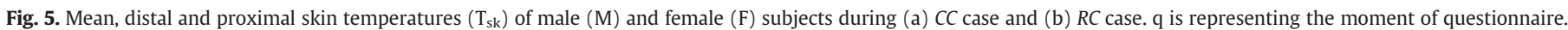
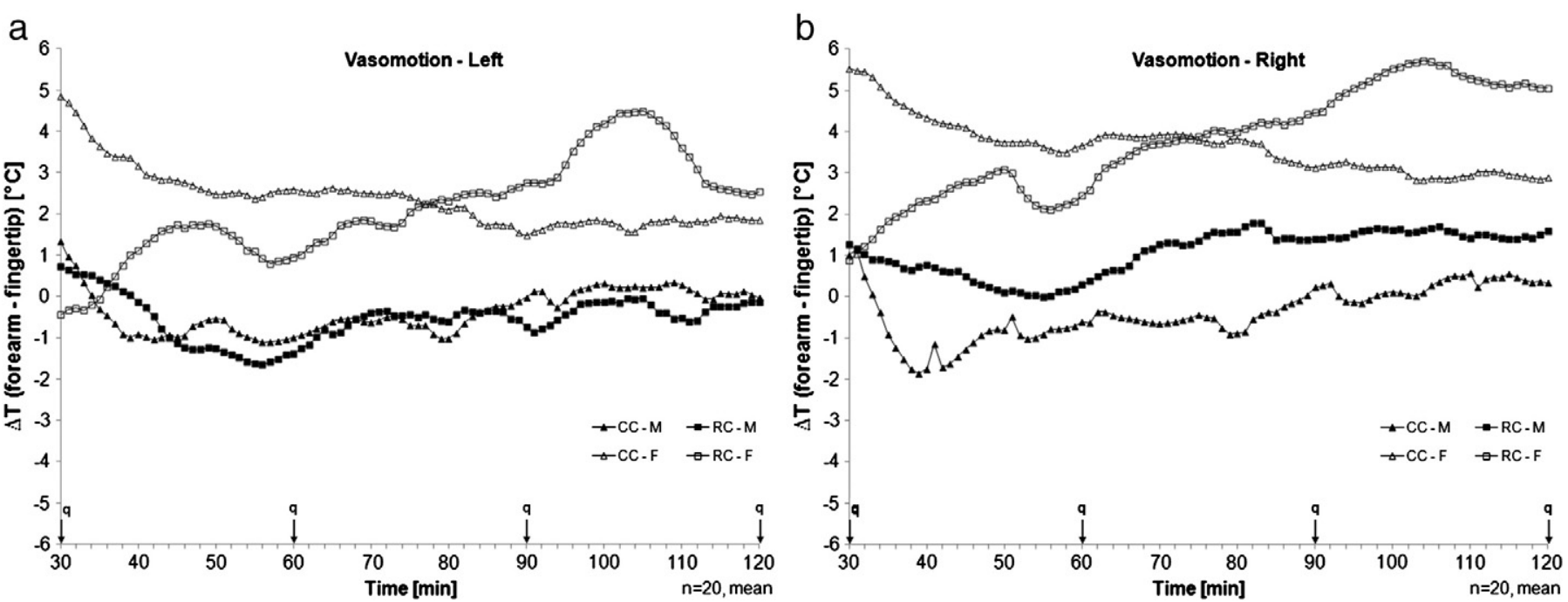

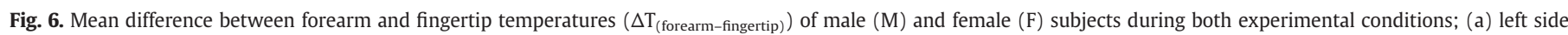
body and (b) right side body. $\mathrm{q}$ is representing the moment of questionnaire. 

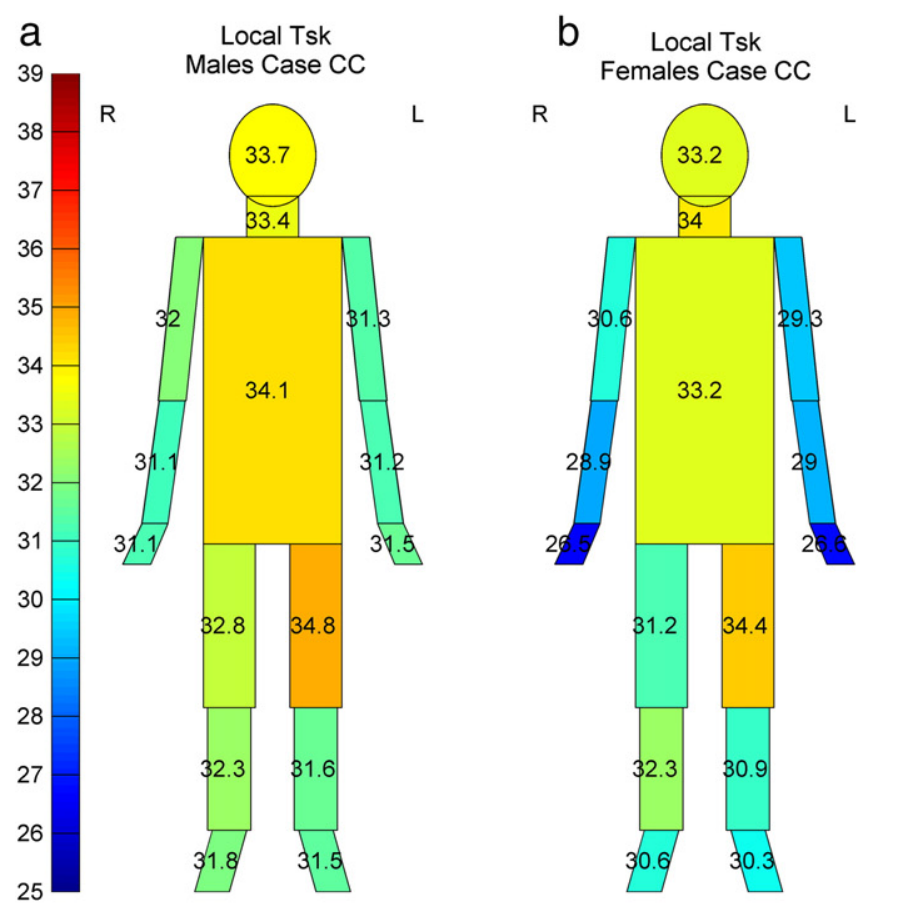

Table 5

Predicted mean vote (PMV) and actual mean vote (AMV) of males and females during both experimental conditions.

\begin{tabular}{lccrrr}
\hline & \multicolumn{2}{l}{ Case $C C$} & & \multicolumn{2}{l}{ Case $R C$} \\
\cline { 2 - 3 } \cline { 5 - 6 } Variable & $\mathrm{M}(\mathrm{n}=10)$ & $\mathrm{F}(\mathrm{n}=10)$ & & $\mathrm{M}(\mathrm{n}=10)$ & $\mathrm{F}(\mathrm{n}=10)$ \\
\hline PMV [-] & $0.3 \pm 0.05$ & $0.1 \pm 0.07^{\wedge}$ & & $0.1 \pm 0.02^{\#}$ & $0.0 \pm 0.02^{\wedge}, \#$ \\
TSV [-] & $-0.3 \pm 0.64^{*}$ & $-0.4 \pm 0.95^{*}, \wedge$ & $-0.3 \pm 0.41^{*}$ & $-0.6 \pm 0.69^{*}, \wedge$ \\
\hline
\end{tabular}

Values are presented as mean $\pm \mathrm{SD}$

* $\mathrm{P}<0.001$ versus PMV.

$\wedge \mathrm{P}<0.05$ versus males.

\# $\mathrm{P}<0.001$ versus $C C$ case (within gender).

a slight decrease in TSV of the females can be observed after $t=90$, which is probably caused by a decrease in mean, distal and proximal skin temperatures (after $\mathrm{t}=80$, Fig. $5 \mathrm{a}$ ). During $R C$ case the females seem to cool down and tend to warm up after $\mathrm{t}=90$ due to a significant $(\mathrm{P}<0.01)$ increased vasoconstrictor tone (Fig. $6, \Delta \mathrm{T}_{\text {forearm-fingertip }}$ increases up to $6{ }^{\circ} \mathrm{C}$ ).

Regarding thermal comfort, the females felt significantly $(\mathrm{P}<0.05)$ more uncomfortable than the males during both cases (Fig. 9). Although the females warmed up after $\mathrm{t}=90$ during $R C$ case and felt warmer (TSV increased from $-1.0 \pm 0.76$ to $-0.7 \pm 0.78$; see Fig. 8 ) they kept feeling slightly uncomfortable $(1.4 \pm 0.97$ on $t=90$ vs $1.4 \pm 0.70$ on $\mathrm{t}=120$ ).
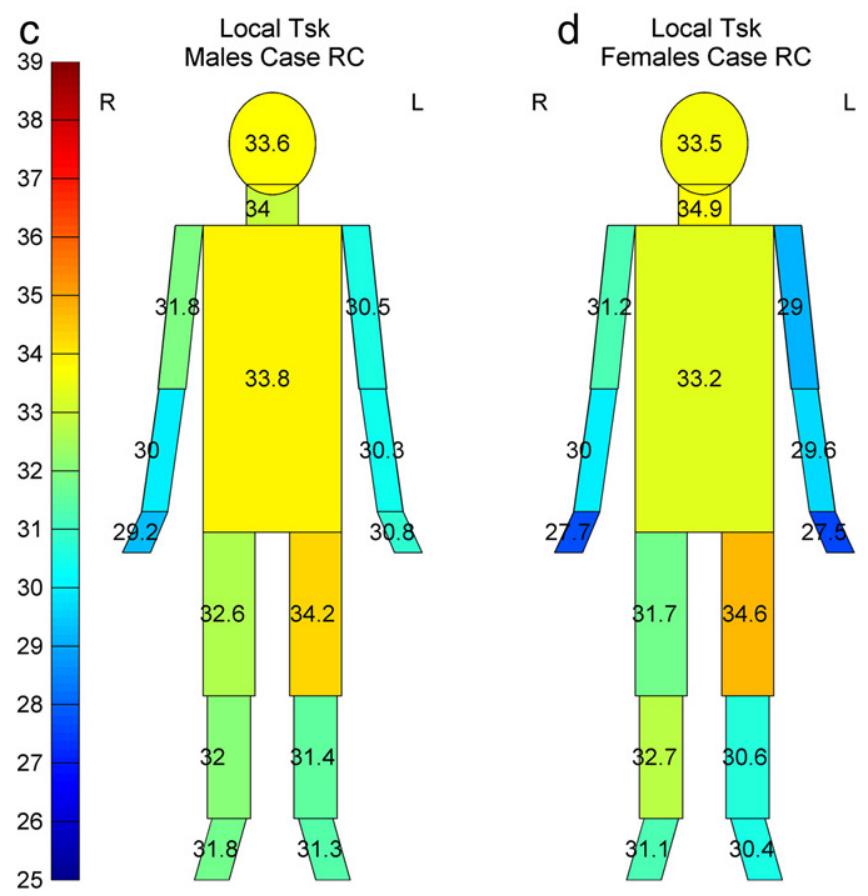

Fig. 7. Mean local skin temperatures; (a) males' CC case (b) females' CC case (c) males' $R C$ case and (d) females' $R C$ case.

\subsection{Subjective responses}

The subjective responses were analyzed from four questionnaires of each case (i.e. Case 1: q2-q5 and Case 2: q6-q9; Fig. 2). With respect to thermal sensation, both the averaged predicted mean vote (PMV, [1]) and the averaged actual mean thermal sensation vote (TSV) are presented in Table 5. The PMV is calculated using the measured physical parameters. The subjective votes were for both genders and cases significantly lower in comparison to the predicted mean vote $(\mathrm{P}<0.001)$. In general, the subjects were feeling significantly colder than predicted. Besides, the females voted significant colder sensations during both conditions in comparison to the males (Fig. 8). For the males no clear time effects could be observed. During CC case

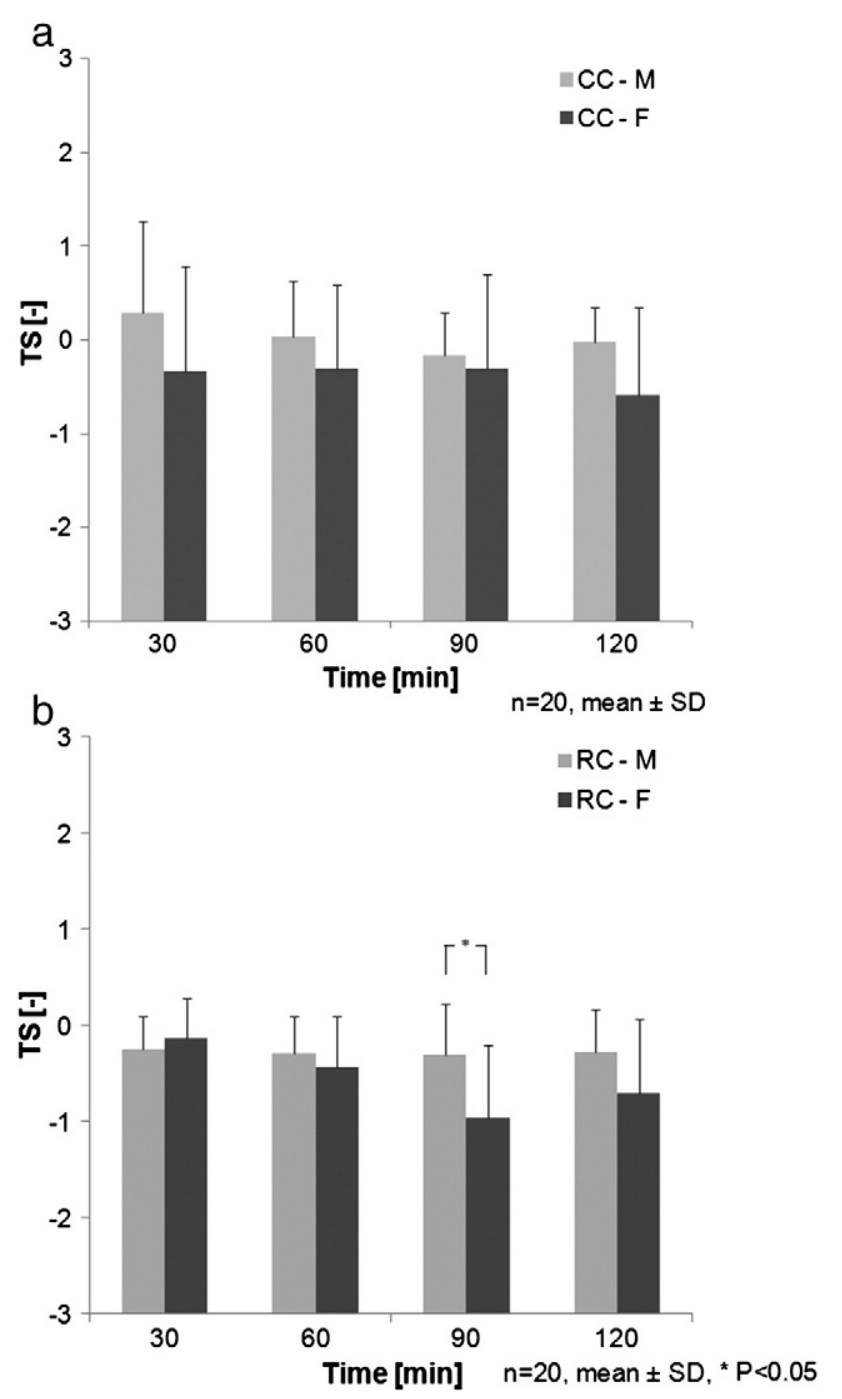

Fig. 8. Actual mean thermal sensation votes; (a) $C C$ case and (b) $R C$ case. 


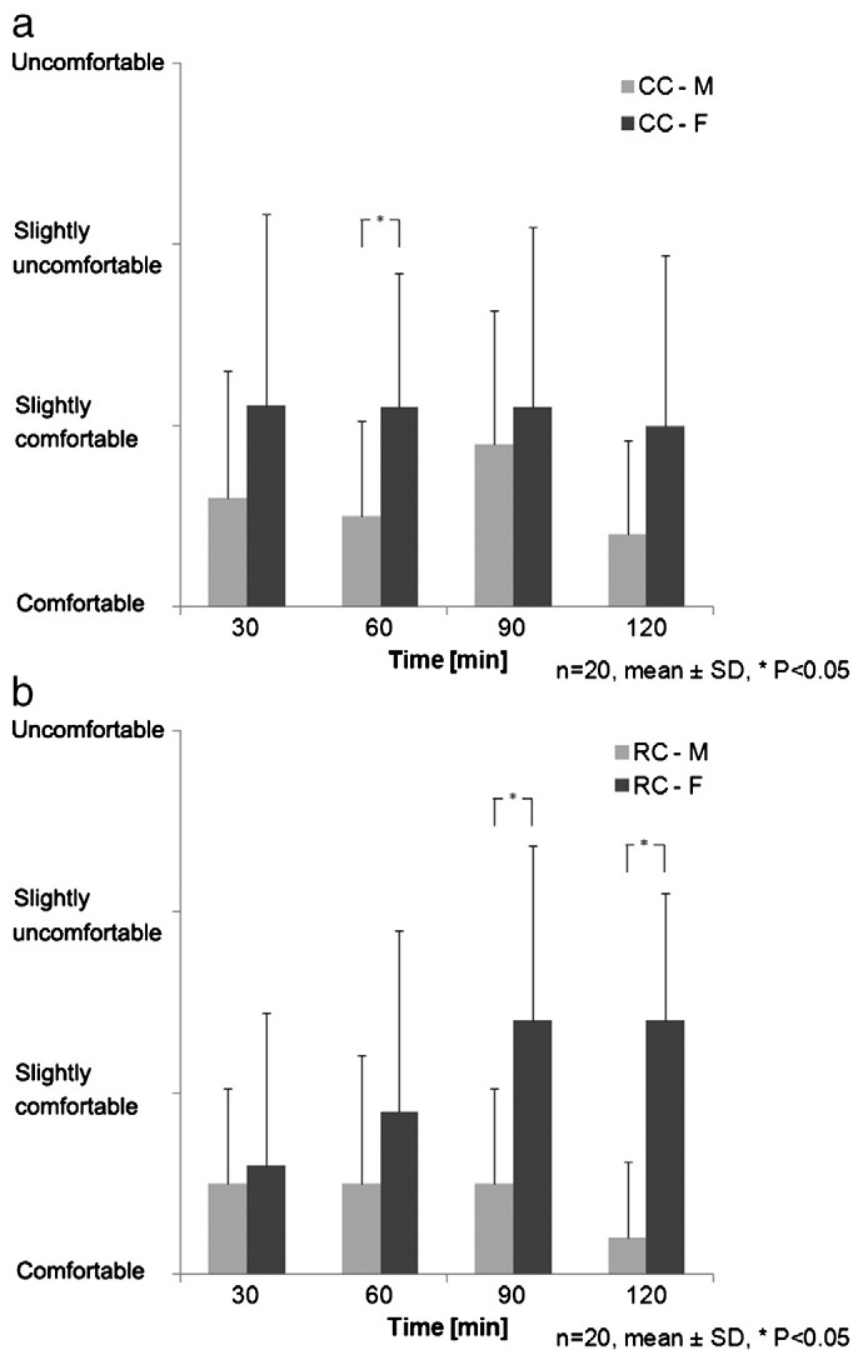

Fig. 9. Mean thermal comfort votes; (a) CC case and (b) $R C$ case.

Furthermore, a higher percentage of females found the thermal environment unacceptable (CC: $30 \%, R C: 25 \%$ ) compared to the male subjects (CC: $0 \%, R C: 5 \%$ ).

\subsubsection{Local effects}

The authors assumed that the discrepancy between the PMV and TSV occurred due to local effects caused by non-uniform environmental conditions. Therefore, the hypotheses were tested that local thermal sensation (local TS) and local skin temperature significantly influenced whole-body thermal sensation (TSV). In Fig. 10 mean local thermal sensations are presented, separately for both cases and gender.

The largest $F$ ratios were found for the uncovered extremities (the hands and forearms both left and right) and the upper arms; i.e. the experimental manipulation had the largest effect on these body parts.

3.2.1.1. Males. The largest correlation for local TS and TSV of the males were found for the hands. Although the correlation was significant, the $r$ was relatively low (around 0.2 ). The largest correlation for local TS versus local skin temperature for the males was found for the right hand $(r=0.4)$.

3.2.1.2. Females. Significant and relatively high correlations were observed between TSV and local TS of right hand $(r=0.73)$, right fore$\operatorname{arm}(r=0.75)$, right upper arm $(r=0.73)$, left hand $(r=0.67)$, left forearm $(r=0.63)$, left upper arm $(r=0.57)$, neck $(r=0.48)$ and head $(r=0.60)$. Furthermore, a significant (relatively high) correlation was

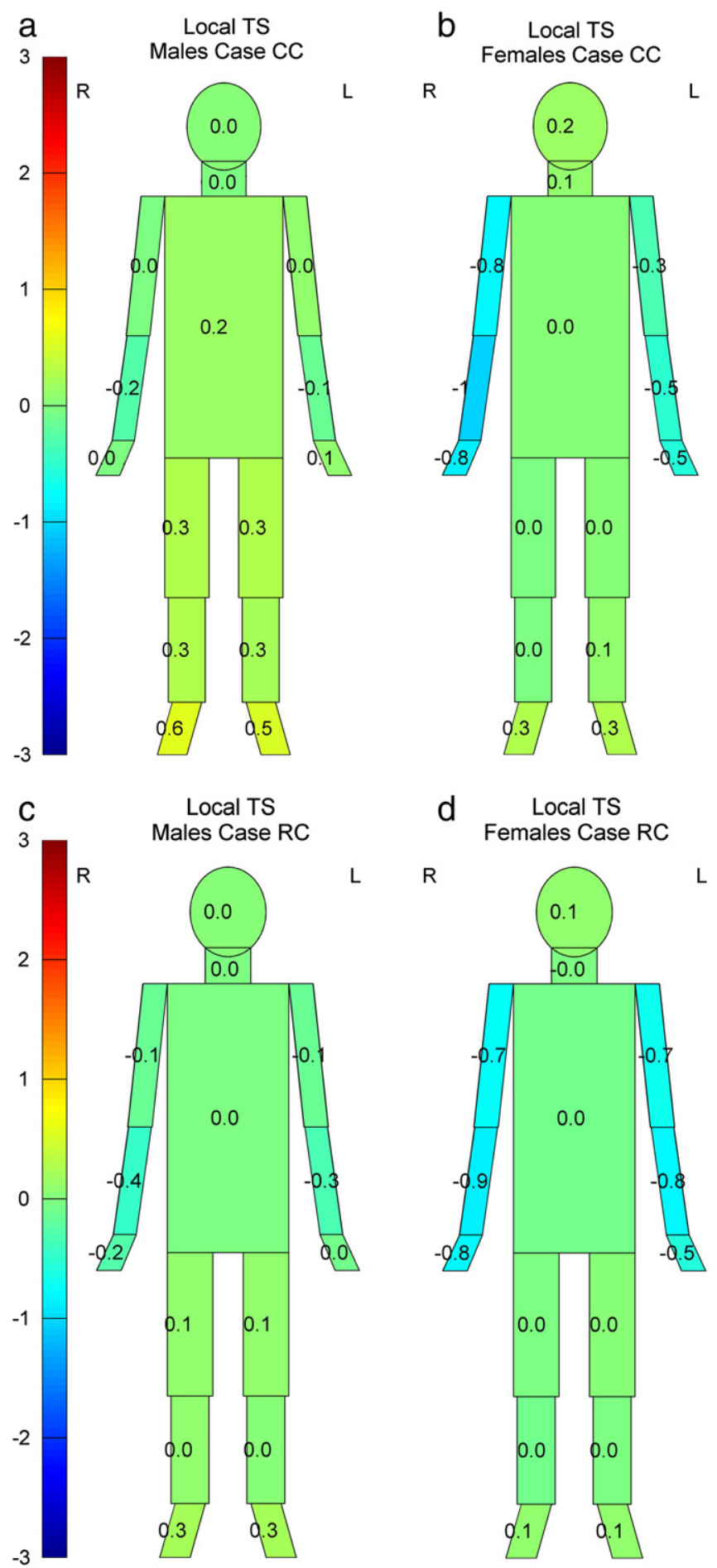

Fig. 10. Mean local thermal sensations; (a) males' CC case (b) females' CC case (c) males' $R C$ case and (d) females' $R C$ case.

found between local TS and skin temperature of right hand $(r=0.53)$, right forearm $(r=0.53)$, right upper arm $(r=0.62)$, left hand $(r=0.39)$ and left upper $\operatorname{arm}(\mathrm{r}=0.44)$.

\subsubsection{Productivity}

The results of the simulated office tasks were analyzed both for the amount of completed additions and correct additions. A priori the results were normalized; the maximum score of each subject was equal to $100 \%$, and all other scores of the subject were related to this score. The results indicate a significant case effect for the average normalized 
a
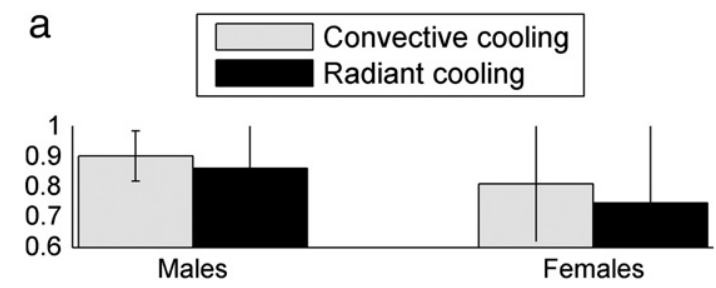

b

Convective cooling

Radiant cooling

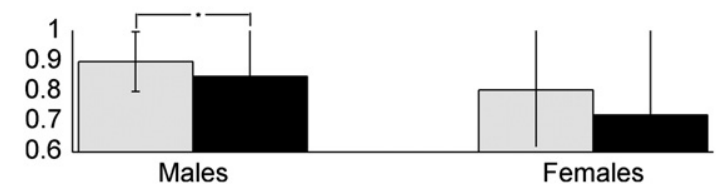

Fig. 11. (a) Average normalized completed additions $\pm S D$ and (b) average normalized correct additions $\pm \mathrm{SD} ;{ }^{*} \mathrm{P}<0.05$.

correct additions of the males, their amount of correct additions were lower during the radiant cooling case in comparison to the convective cooling case $(P<0.05)$. No significant case effects were found within the female group (Fig. 11). Furthermore, no significant effects were found between the genders.

\section{Discussion}

In this study the differences in physiological responses, thermal comfort and productivity between males and females in response to non-uniform environmental conditions were studied. The subjects were exposed to two different conditions: a convective cooling situation ( $C C$ case) and a radiant cooling situation ( $R C$ case).

The results show that in general the females were more uncomfortable in comparison to the males under the same environmental conditions. Although the mean air velocity during CC case was higher for the females compared to the males, the same trend in differences between the genders in physiological and subjective responses were observed for both $C C$ and $R C$ cases. The distal skin temperatures of the females were significantly lower compared to the males. For the females a significant relation was found between the local skin temperatures of the hands, forearms and upper arms and the related (local) thermal sensations.

For both genders the extent of vasoconstriction was larger at the right side of the body compared to the left side. This is probably caused by the positioning of the inlet (at the right side of the subject). Furthermore, all subjects were right-handed and operated therefore the computer mouse with their right hand, which may explain why their right hand was colder compared to their left one [40].

The calculated power, based on the results achieved for $R C$ case, for the whole-body thermal sensation votes (TSV) is $40 \%(\alpha=0.05)$. In advance, a smaller standard deviation was expected on the results. Therefore, for future studies it is advisable to include more subjects per sample to enlarge the power of the results. In case a difference in TSV between two groups of 0.5 and a maximum standard deviation of \pm 0.5 is considered, the minimum amount should be 16 persons per sample.

However, with respect to the results found in this study, a clear trend is visible in differences in thermal sensation and comfort between the two genders.

For females a high correlation was found between the local thermal sensation of the hands, forearms and upper arms and whole body thermal sensation (TSV). This is in line with previous studies where women complained about cold extremities and, in fact, exhibited cooler distal skin regions than men [18,20,41]. Krauchi et al. [42] found in a study on cold extremities and difficulties initiating sleep, under 2800 subjects, that women complain 4.5 times more about cold hands and feet. In this study no significant differences were found for the feet, which might be explained by the posture of subjects during the experiments. During $R C$ case furthermore the increased floor temperature could be an explanation.

These studies found no significant differences in local thermal discomfort levels at the same local skin temperature levels between genders. However, in the presented study significant negative effects of low (in comparison to proximal skin temperature) local skin temperatures were found for the uncovered body parts on local thermal sensation (TS) of these body parts. Yet, at lower local skin temperature levels of the proximal body parts no significant differences in TS of these body parts could be observed between males and females (Figs. 7 and 10).

Following the above the significant differences which were found in TSV (actual mean thermal sensation vote) are caused by local TS of the distal body parts and distal skin temperatures. This finding is confirmed by the significant and relatively high correlation between TSV, local TS and local skin temperatures. Note that this only applies for the female group. This result is in line with the results found by Krauchi et al. [42], who found that thermal discomfort of cold hands is correlated with a cool finger temperature. Contrary, Zhang et al. [16] found that the most important explaining parameters for TSV are the forehead, neck and chest. The experiments in that study were performed using an air-sleeve which was attached to one specific body part. Subsequently, the influence on TSV of cooling or warming this body part was studied. Afterwards, the developed model was validated against experimental results obtained from measurements in vehicles (very inhomogeneous environment). In our study, the approach was to expose the subjects to more realistic conditions with respect to the built environment. The intention was, however, to impose sufficient differences between and within the cases to achieve clear results and to draw conclusions for less critical situations which may occur in practice. The differences in setup between this study and the study of Zhang et al. [16] may explain the different conclusions.

The lower female skin temperatures, both distal and proximal can be explained morphologically [43]. Women have, among others, a larger peripheral heat sink and greater body insulation when vasoconstricted (except hands and feet). The latter might explain the significant correlation between skin temperature and local TS of the distal body parts. Another explanation for the cold extremities could be the increase in progesterone levels during the luteal phase, which cause an increase in the internal threshold temperature for vasodilation and sweating. Consequently, the extremities remain colder [9].

Compared to Fanger [44], the mean skin temperatures, of both males and females, which were found in our study were slightly, but significant, lower than the comfortable skin temperatures found in the reviewed studies. This might indicate that the subjects in the present study are at the cold side of comfort. However, one could argue whether the mean skin temperature is a good predictor for thermal comfort [8].

Previous studies found that women are more dissatisfied with their thermal environment in comparison to males [18,45,46], which is found in this study as well (Fig. 9). For a non-uniform environment, this was also found by Hashiguchi et al. [13].

In our experiments, subjects in the age between 20 and 29 years were studied. From literature we know that temperature sensitivity decreases with age [47]. Older adults tend to fail sensing a thermal imbalance and/or they are failing in responding to it appropriately [48]. In addition, Kingma et al. [9] concluded that the thermoneutral zone (TNZ) is narrower for older adults than for young ones. Furthermore, the TNZ for females is shifted upward compared to the TNZ of males. However, the exact range of the TNZ for both groups (females and older adults) is yet unknown. Consequently, thermal sensation and comfort are affected by physiological aging and age related behavioral changes [49]. Schellen et al. [50] found that older male subjects prefer higher operative temperatures compared to their younger counterparts 
to achieve thermal comfort. Following the above, the differences found in this study and the effects of local parameters on thermal sensation and comfort may enlarge when the age increases.

Olesen [14] stated that draught under warm conditions (i.e. convective cooling $(C)$ might be comfortable and therefore could reduce the energy-use in terms of cooling. In this study no significant differences in whole body thermal sensation (TSV) were observed between $C C$ and $R C$ cases for both genders. The predicted mean vote (PMV), however, did indicate significant case effects (Table 5) where CC case is assessed as warmer. Remark that these effects are within the accuracy of PMV ( \pm 0.5$)$. For both genders, the TSV was significantly lower than the PMV. Thus, the subjects were feeling significantly colder than predicted. Especially, for the females this resulted in a slightly uncomfortable situation (Fig. 9). For the females, the results indicate that $R C$ case is more uncomfortable than $C C$, but this is not significant.

The experiments were conducted during the winter/early spring period (December-March), which could have influenced the thermal perception of the subjects and may explain partly the sensations on the cold side of neutral. However, the subjects were already 1-1.5 h in the laboratory prior to the start of the experiment. Furthermore, the focus in this study was not specifically on the effects of cooling compared to warming, but on the differences between gender in response to a non-uniform environment. Nevertheless, already at relatively low outside temperatures a cooling demand can exist in office buildings, due to relatively high internal heat loads, well insulated building envelopes and solar contribution. Therefore it is possible that occupants of typical office buildings can be exposed to cooling conditions early in the season and even in the winter.

The differences in set-up conditions of $R C$ case (AC) are considered as small $(\triangle \mathrm{PMV}=0.2)$. The difference between males and females in AMV for case $C C$ is smaller than for case $R C$, while the opposite is true for the PMV. Therefore we conclude that the difference in AMV of both genders is not related to the differences in set-up conditions.

With respect to the prediction of thermal comfort obtained using PMV-index, the sensitivity of the boundary conditions (i.e. clothing insulation and activity level) on the results should be taken into account. For example, Ferraro et al. [51] found a lower ( 5-10\%) metabolic rate for sedentary females compared to males. Particularly, in field studies errors were found regarding the estimation of clothing insulation and activity levels; these errors contribute to the inaccuracy of the PMV [4].

From the productivity results no significant conclusions can be drawn, probably because the sample size is too small with respect to this. However, the results show consistency in the direction of change for both genders between the convective cooling and radiant cooling conditions. More research is needed to further elaborate on this.

The presented data do not allow concluding that draught under warm conditions is acceptable in terms of thermal comfort.

In terms of cooling, it can be concluded that the set-points for females need to be increased to improve satisfaction with thermal environment, which is in agreement with Choi et al. [45].

\section{Conclusion}

In this study both males and females were exposed to nonuniform environmental conditions. Prior to the experiments, the predicted mean vote (PMV) was calculated. For both experimental conditions the predicted mean vote was approximately neutral $(P M V \approx 0)$. The results of this study indicate:

1. Under non-uniform conditions, the actual mean thermal sensation votes (TSV) significantly differ from the PMV for both genders. The subjects were feeling significantly colder than predicted.

2. Females are more uncomfortable and dissatisfied under the same environmental conditions compared to males. Note that in this study mean thermal sensation was colder than predicted. For thermal sensations warmer than predicted, this should be investigated further.

3. For females, local thermal sensation and skin temperature of the extremities (hands and arms) are of high importance for whole body thermal sensation TSV. For males, local thermal sensation and skin temperature of the extremities are less important.

4. In terms of cooling, the operative temperatures for females need to be increased by $\sim 1.2 \mathrm{~K}$ to improve satisfaction with the thermal environment.

\section{Acknowledgements}

The authors would like to thank Dr. B. Kingma for his valuable contribution on the analyses regarding the influence of local effects on whole body thermal sensation. Furthermore, they want to express their gratitude to the staff of the laboratory of the Unit Building, Physics and Services of Eindhoven University of Technology for their assistance. Appreciation is also expressed to the subjects who participated in the experiments. This study was supported by AgentschapNL (EOS-LT 02003), their financial contribution is gratefully acknowledged.

\section{References}

[1] Fanger O. Thermal comfort. Copenhagen: Danish Technical University; 1970.

[2] ASHRAE. Standard 55: thermal environmental conditions for human occupancy; 2010.

[3] EN-ISO 7730: ergonomics of the thermal environment - analytical determination and interpretation of thermal comfort using calculation of the PMV and PPD indices and local thermal comfort criteria. International Standards Organization; 2005.

[4] van Hoof J. Forty years of Fanger's model of thermal comfort: comfort for all? Indoor Air 2008;18:182-201.

[5] Brager GS, de Dear R. A standard for natural ventilation. Ashrae J 2000;42:21-8.

[6] Humphreys MA, Nicol JF. The validity of ISO-PMV for predicting comfort votes in every-day thermal environments. Energy Build 2002;34:667-84.

[7] Parsons KC. Human thermal environments: the effects of hot, moderate, and cold environments on human health, comfort, and performance. Taylor \& Francis; 2003.

[8] Kingma B, Schellen L, Frijns A, van Marken Lichtenbelt W. Thermal sensation: a mathematical model based on neurophysiology. Indoor Air 2011;22:253-62.

[9] Kingma B, Frijns A, Van Marken Lichtenbelt W. The thermoneutral zone: implications for metabolic studies. Front Biosci 2012;E4:1975-85.

[10] Karjalainen S. Thermal comfort and gender: a literature review. Indoor Air 2011;22(2): 96-109.

[11] International Energy Agency (IEA). ECBCS. www.ecbcs.org. 2011; last visited on 23.04.2012.

[12] Juusela MA. Guidebook to IEA ECBCS Annex 37. Heating and cooling with focus on increased energy efficiency and improved comfort. Espoo: VTT Building and Transport; 2003.

[13] Hashiguchi N, Feng Y, Tochihara Y. Gender differences in thermal comfort and mental performance at different vertical air temperatures. Eur J Appl Physiol 2010;109:41-8.

[14] Olesen BW. International standards for the indoor environment. Indoor Air 2004; 14 $18-26$.

[15] Arens E, Zhang H, Huizenga C. Partial- and whole-body thermal sensation and comfort - part II: non-uniform environmental conditions. J Therm Biol 2006;31:60-6.

[16] Zhang H, Arens E, Huizenga C, Han T. Thermal sensation and comfort models for non-uniform and transient environments: part I: local sensation of individual body parts. Build Environ 2010;45:380-8.

[17] Breesch H, Bossaer A, Janssens A. Passive cooling in a low-energy office building. Sol Energy 2005;79:682-96.

[18] Karjalainen S. Gender differences in thermal comfort and use of thermostats in everyday thermal environments. Build Environ 2007;42:1594-603.

[19] Lan L, Lian Z, Liu W, Liu Y. Investigation of gender difference in thermal comfort for Chinese people. Eur J Appl Physiol 2008;102:471-80.

[20] Mozaffarieh M, Fontana Gasio P, Schotzau A, Orgul S, Flammer J, Krauchi K. Thermal discomfort with cold extremities in relation to age, gender, and body mass index in a random sample of a Swiss urban population. Popul Health Metrics 2010;8:17-22.

[21] Djongyang N, Tchinda R, Njomo D. Thermal comfort: a review paper. Renew Sustain Energy Rev 2010;14:2626-40.

[22] Baker FC, Mitchell D, Driver HS. Oral contraceptives alter sleep and raise body temperature in young women. Pflugers Arch 2001;442:729-37.

[23] Durnin JV, Rahaman MM. The assessment of the amount of fat in the human body from measurements of skinfold thickness. Br J Nutr 1967;21:681-9.

[24] Lohman TG, Roche AF, Martorell R. Anthropometric standardization reference manual: Champaign; 1988.

[25] EN-ISO 9920: Ergonomics of the thermal environment - estimation of thermal insulation and water vapour resistance of a clothing ensemble. International Standards Organization; 2009. 
[26] Mccullough EA, Jones BW, Tamura T. A database for determining the evaporative resistance of clothing. ASHRAE Trans 1989;95:316-28.

[27] Mccullough EA, Olesen BW, Hong S. Thermal insulation provided by chairs ASHRAE Trans 1994;100(1):795-802.

[28] Roulet CA, Rossy JP, Roulet Y. Using large radiant panels for indoor climate conditioning. Energy Build 1999;30:121-6.

[29] Miriel J, Serres L, Trombe A. Radiant ceiling panel heating-cooling systems: experimental and simulated study of the performances, thermal comfort and energy consumptions. Appl Therm Eng 2002;22:1861-73.

[30] KNMI. Maandoverzicht van het weer in Nederland. www.knmi.nl. 2011; last visited on 23.04.2012

[31] House JR, Tipton MJ. Using skin temperature gradients or skin heat flux measurements to determine thresholds of vasoconstriction and vasodilatation. Eur J Appl Physiol 2002;88:141-5.

[32] Sessler DI. Skin-temperature gradients are a validated measure of fingertip perfusion. Eur J Appl Physiol 2003;89:401-2 [author reply 3-4].

[33] van Marken Lichtenbelt WD, Daanen HAM, Wouters L, Fronczek R, Raymann RJEM, Severens NMW, et al. Evaluation of wireless determination of skin temperature using iButtons. Physiol Behav 2006;88:489-97.

[34] EN-ISO 9886: ergonomics - evaluation of thermal strain by physiological measurements. International Standards Organization; 2004.

[35] Loomans MGLC. The measurement and simulation of indoor air flow. Eindhoven: Eindhoven University of Technology; 1998.

[36] EN-ISO 7726: ergonomics of the thermal environment - instruments for measuring physical quantities. International Standards Organization; 2001.

[37] EN-ISO 10551: ergonomics of the thermal environment - assessment of the influence of the thermal environment using subjective judgement scales. International Standards Organization; 1995.

[38] Kildeso J, Wyon D, Skov T, Schneider T. Visual analogue scales for detecting changes in symptoms of the sick building syndrome in an intervention study. Scand J Work Environ Health 1999;25:361-7.

[39] Toftum J, Wyon DP, Svanekjaer H, Lantner A. Remote performance measurement (RPM) - a new, internet-based method for the measurement of occupant performance in office buildings. Indoor Air 2005, the 10th International Conference on Indoor Air Quality and Climate. Beijing, China; 2005. p. 357-61.

[40] Huizenga C, Zhang H, Arens E, Wang D. Skin and core temperature response to partial- and whole-body heating and cooling. J Therm Biol 2004;29:549-58.

[41] Nagashima K, Yoda T, Yagishita T, Taniguchi A, Hosono T, Kanosue K. Thermal regulation and comfort during a mild-cold exposure in young Japanese women complaining of unusual coldness. J Appl Physiol 2002;92:1029-35.

[42] Krauchi K, Gasio PF, Vollenweider S, Von Arb M, Dubler B, Orgul S, et al. Cold extremities and difficulties initiating sleep: evidence of co-morbidity from a random sample of a Swiss urban population. J Sleep Res 2008;17:420-6.

[43] Burse RL. Sex-differences in human thermoregulatory response to heat and cold stress. Hum Factors 1979;21:687-99.

[44] Fanger PO. Assessment of man's thermal comfort in practice. Br J Ind Med 1973;30: 313-24.

[45] Choi J, Aziz A, Loftness V. Investigation on the impacts of different genders and ages on satisfaction with thermal environments in office buildings. Build Environ 2010;45:1529-35.

[46] Cena K, de Dear R. Thermal comfort and behavioural strategies in office buildings located in a hot-arid climate. J Therm Biol 2001;26:409-14.

[47] Huang HW, Wang WC, Lin CC. Influence of age on thermal thresholds, thermal pain thresholds, and reaction time. J Clin Neurosci 2010;17:722-6.

[48] Van Someren EJ, Raymann RJ, Scherder EJ, Daanen HA, Swaab DF. Circadian and age-related modulation of thermoreception and temperature regulation: mechanisms and functional implications. Ageing Res Rev 2002;1:721-78.

[49] van Hoof J, Hensen JLM. Thermal comfort and older adults. Gerontechnology 2006;4:223-8.

[50] Schellen L, Lichtenbelt WDV, Loomans MGLC, Toftum J, de Wit MH. Differences between young adults and elderly in thermal comfort, productivity, and thermal physiology in response to a moderate temperature drift and a steady-state condition. Indoor Air 2010;20:273-83.

[51] Ferraro R, Lillioja S, Fontvieille AM, Rising R, Bogardus C, Ravussin E. Lower sedentary metabolic rate in women compared with men. J Clin Invest 1992;90:780-4. 